\title{
Knowledge, Practices, and Environmental and Occupational Health Risks Associated with Electronic Waste Recycling in Cotonou, Benin
}

\author{
M. G. Karel Houessionon ${ }^{*}{ }^{(0)}$, Niladri Basu2 ${ }^{2}$ Catherine Bouland ${ }^{3}$, N. Marius Kedote1, \\ Benjamin Fayomi ${ }^{4}$, N. Julius Fobilis, Edgard-Marius Ouendo ${ }^{1}$
}

\author{
${ }^{1}$ Regional Institute of Public Health Comlan Alfred Quenum, University of Abomey-Calavi, Ouidah, Benin \\ ${ }^{2}$ Department of Natural Resource Sciences, McGill University, Montreal, Quebec, Canada \\ ${ }^{3}$ School of Public Health, Université Libre de Brussels, Bruxelles, Belgium \\ ${ }^{4}$ Occupationnal Health and Environment Research Unit, University of Abomey-Calavi, Cotonou, Benin \\ ${ }^{5}$ School of Public Health, University of Ghana, Accra, Ghana \\ Email: *karelhouessionon@yahoo.fr
}

How to cite this paper: Houessionon, M.G.K., Basu, N., Bouland, C., Kedote, N.M., Fayomi, B., Fobil, N.J. and Ouendo, E.-M. (2021) Knowledge, Practices, and Environmental and Occupational Health Risks Associated with Electronic Waste Recycling in Cotonou, Benin. Occupational Diseases and Environmental Medicine, 9, 33-48.

https://doi.org/10.4236/odem.2021.92004

Received: January 27, 2021

Accepted: March 14, 2021

Published: March 17, 2021

Copyright () 2021 by author(s) and Scientific Research Publishing Inc. This work is licensed under the Creative Commons Attribution International License (CC BY 4.0).

http://creativecommons.org/licenses/by/4.0/

\section{(c) (i) Open Access}

\begin{abstract}
Objective: The e-waste recycling is increasing worldwide, yet there remain outstanding environmental and occupational health concerns. Most research conducted on e-waste recycling has focused on only few countries (e.g., China, Ghana), thus there is a need to increase understanding of e-waste workers' (recyclers') knowledge and practices in other locations, that is purpose of this study. Methods: In a cross-sectional study conducted in Cotonou, Benin, 45 e-waste recyclers were interviewed from September to November 2018. Survey data was collected concerning their demographics, professional practices, and knowledge of occupational and environmental risks associated with e-waste recycling. Results: Most participants reported the following methods of material recovery of electronic items in declining orders: dismantling $(97.8 \%)>$ sorting $(91.1 \%)>$ incinerating $(88.9 \%)$. Only $44.2 \%$ of the recyclers reported wearing $\geq 1$ piece of personal protective equipment (PPE). More than $90 \%$ of e-waste workers noted that they disposed the e-waste in natural sites. About half, $46.7 \%$ believed that e-waste can pollute water and $71.1 \%$ considered that it can pollute air and soil. Recyclers reported several diseases including respiratory (67.4\%), heart $(62.8 \%)$, eye (65.1\%), kidney (41.9\%) and cancers (30.2\%) could be linked to their work, respectively. Interestingly, we also found associations between the number of electronic items dismantled per month and self-report symptoms from the e-waste recyclers such as finding blood in urine and stool, wounds, dizziness, and itchy skin. Our results also indicated associations between the number of
\end{abstract}


hours worked per day and blood in urine, dizziness, itchy skin and airway obstruction. Conclusion: To our knowledge this is the first study to interview e-waste workers in Benin. Doing this increase understanding of their work practices and knowledge to help inform intervention and prevention activities.

\section{Keywords}

E-Waste, Recycling, Occupational Health, Environment, Knowledge, Practice

\section{Introduction}

Population growth has increased the need for the use of electrical and electronic equipment [1]. This has increased the production of electrical and electronic waste (e-waste) all over the world [2]. In 2016, the quantity of e-waste reached approximately 44.7 million tons worldwide, with a production of approximately $6.1 \mathrm{~kg} /$ inhabitant. This number is projected to grow to 52.2 tons worldwide in 2021 or $6.8 \mathrm{~kg} /$ inhabitant [3]. Much of the world's e-waste is transferred from high-income countries to those considered to be developing countries [4] [5] [6] where many are dependent upon this recycling activity for employment [7] [8].

Africa has the lowest rate of e-waste production worldwide (2.2 million metric tons and $1.9 \mathrm{~kg} /$ inhabitant), and it is also a region in which few of the electronics used are recycled with estimates suggesting that less than $1 \%$ of e-waste formally collected is recycled [3]. Africa generates relatively little e-waste but it receives thousands of tons of e-waste each year from developed countries [9]. The e-waste that is processed across Africa contains chemical substances that potentially pose risks to the environment including (air, soil and water) [8] [10] as well as health risks to e-waste the workers [7] [8] [11] [12]. Several studies have shown that recyclers have little knowledge of the health and environmental risks associated with the e-waste recycling activities [7] [13] as they are primarily motivated by financial benefits [14]. Few recyclers are aware of the possible links between their activities and environmental pollution, as well as with diseases they might get [7]. For example, studies by Ohajinwa, Van Bodegom [13] and Black, Karki [15] showed that few recyclers wear PPE in their daily activities.

There are a handful of studies concerning occupational health and environmental risks among e-waste recyclers across Africa, mainly from Ghana [16] [17] [18] and Nigeria [13] [19] [20]. These studies emphasize potential prevention and intervention strategies [21]. However, in most African countries there is limited research on the demographics, knowledge and practices of e-waste recyclers. Therefore, the objectives of this study are: 1) to increase understanding of these factors (knowledge and practices) by interviewing e-waste recyclers of Cotonou, Benin, and 2) to find an association between knowledge, practices and self-reported health repercussion. 


\section{Methods}

\subsection{Study Design}

A cross-sectional, mixed-method research study was conducted in which quantitative and qualitative methods were used. This study was conducted from September to November 2018 in Cotonou. Cotonou is home to almost all e-waste recycling activities in Benin, and therefore most recyclers. All study participants were e-waste workers who signed a consent form. Data were collected through interviews anonymously. Ethical approval for this work was received from the Research Ethics Committee of the Institute of Applied Biomedical Sciences of Benin (CER-ISBA) (reference: No 113-07/09/18).

\subsection{Study Population}

E-waste recycling activities in Benin (like most other settings) are largely conducted in the informal sector and thus deemed illegal [22]. This prevents data collection regarding the number of e-waste recyclers in Benin. As such, it is difficult to enumerate the number of employees in the e-waste sector and to also recruit participants in a truly representative and unbiased manner. Nonetheless, as the first study of its kind in Benin, here we adopted a convenience sampling strategy and thus recruited all e-waste recyclers working in Cotonou who consented to participate during the investigation period. In doing so, we were able to recruit a total of 45 recyclers from six different sites such as: Agla, Barrière, Hindé, Kpankpan, Adogléta and Donatin (see Figure 1). This could have an impact on the representativeness of the e-waste recyclers. Nevertheless, this bias

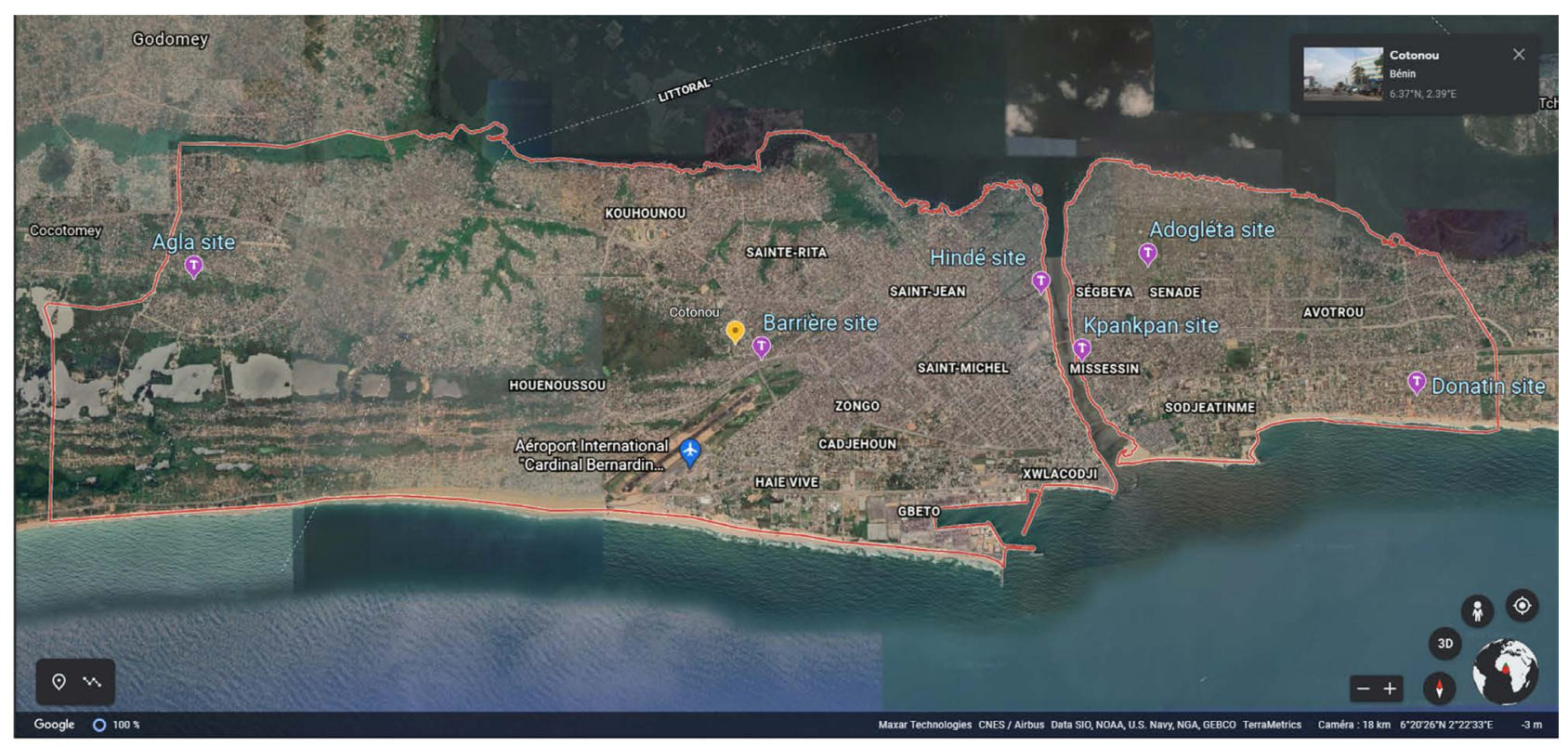

Legend:

T Recycling sites under study

Source: Google earth, 2021.

Figure 1. Mapping of study sites. 
was controlled by including all e-waste recyclers available during the study period and at several (larger) recycling sites.

To participate in this study, it was necessary for the e-waste recyclers to be active for at least 3 months and residing in Cotonou. Recyclers who work in Cotonou but reside elsewhere were not included in this study. For the participants under 18 years old, permission from parents or guardians was obtained prior to any formal engagement.

\subsection{Data Collection and Analysis}

Data collection focused on obtaining information on the workers' demographics and professional practices, a proxy for work intensity and thus exposure. In addition, we surveyed them on their knowledge of the risks associated with their activities. The survey was based on a standardized questionnaire [23] and adapted to the Benin context concerning self-reported health information. The adapted questionnaire was pre-tested with 5 e-waste workers in Abomey-Calavi, a neighboring city of Cotonou, to avoid polluting the study area. Surveys were completed through individual face to face interviews. In addition, we made global and direct observations of the activity in the field and realized this through the development of observation grids. To these different techniques, we added the documentary analysis which made it possible to collect information to describe the context of recycling e-waste in Cotonou.

The survey sheets were manually scanned and entered a pre-developed mask using SPSS version 21.0 software. The collected data were initially subjected to descriptive statistical analysis. Next, bi-variate association tests were conducted (using the Chi-square test with a significance level of 5\%) to characterize possible links between recyclers' knowledge and their ways of organizing recycling activities. The graphs were generated using Microsoft Excel 2013.

In terms of qualitative data, triangulation of the information collected revealed similarities in the responses of study participants. Pictures taken in the field illustrated some of the recyclers' practices.

\section{Results}

\subsection{Professional Profile of Recyclers}

All participants in our study were male, and their average age was 24 years and ranged from 16 to 45 years. Most of the workers were Beninese (57.8\%) and the rest hailed from Niger. Almost half (47.7\%) of the study participants have no level of education while $36.4 \%$ and $15.9 \%$ respectively have a primary and secondary level of education. Most of the recyclers are single (62.2\%) e while $20 \%$ are married and $18.8 \%$ are in a common-law partnership.

In terms of income, $38.6 \%$ of the recyclers earn between 50 and 100 thousand CFA francs per month, and $34.1 \%$ of them have a monthly income below 50 thousand CFA francs. It should be noted that $20.5 \%$ of them have incomes between 100 and 200 thousand while $6.8 \%$ earn more than 300 thousand. 
Twenty percent (20\%) of recyclers have worked in e-waste recycling for less than one year, while $26.7 \%$ of them have worked between 1 and 3 years, $13.3 \%$ have worked between 3 and 5 years, 17.8\% have worked between 5 and 10 years, and $22.2 \%$ have worked for more than 10 years recycling e-waste. The majority $(71.1 \%)$ of the recyclers surveyed engage in no other professional activity except e-waste recycling. It is noted that $8.8 \%$ of recyclers are ordinary craftsmen while $19.9 \%$ are craftsmen who may be exposed to heavy metals through their work tasks (e.g., blacksmith, welder, mechanic and turning adjuster).

When surveyed about the e-waste recycling practices, most of the perform multiple tasks with most indicating that they dismantle (97.8\%), sort (91.1\%), incinerate $(88.9 \%)$ and collect $(77.8 \%)$ of e-waste. In addition, many of them sell e-waste spare parts $(66.7 \%)$ and some (8.9\%) will engage in repairing the broken electronics received.

Dismantling is the recycling method most adopted by recyclers in Cotonou. This method allows them to separate the different materials from each electrical and electronic equipment before sorting or incineration. We queried workers on the number of specific electronic items that they dismantled each month, and the proportions are provided in Figure 2. On average, the decreasing rank-order of items most dismantled each month included: Mobile phone (84 units) $>$ Iron (41 units) $>$ Batteries (38 units) $>$ Disk drives (35 units) $>$ Decoder (32 units) $>$ Fans (21 units) $>$ Desktop computers (18 units) $>$ Radio (16 units) $>$ Air conditioners (13 units) $>$ CRT TVs (12 units) $>$ Refrigerators ( 9 units) $>$ Laptop (8 units) > Plasma TV (7 units) > washing machine ( 6 units). These findings demonstrated that a range of electronic items are dismantled in Cotonou (Figure 3). More than $80 \%$ of recyclers dismantle more than 5 units of each type of e-waste per month. About $20 \%$ of recyclers dismantle between 10 and more than 30 units of each type of e-waste per month.

Most (88.5\%) of the recyclers interviewed said they incinerated at least once a

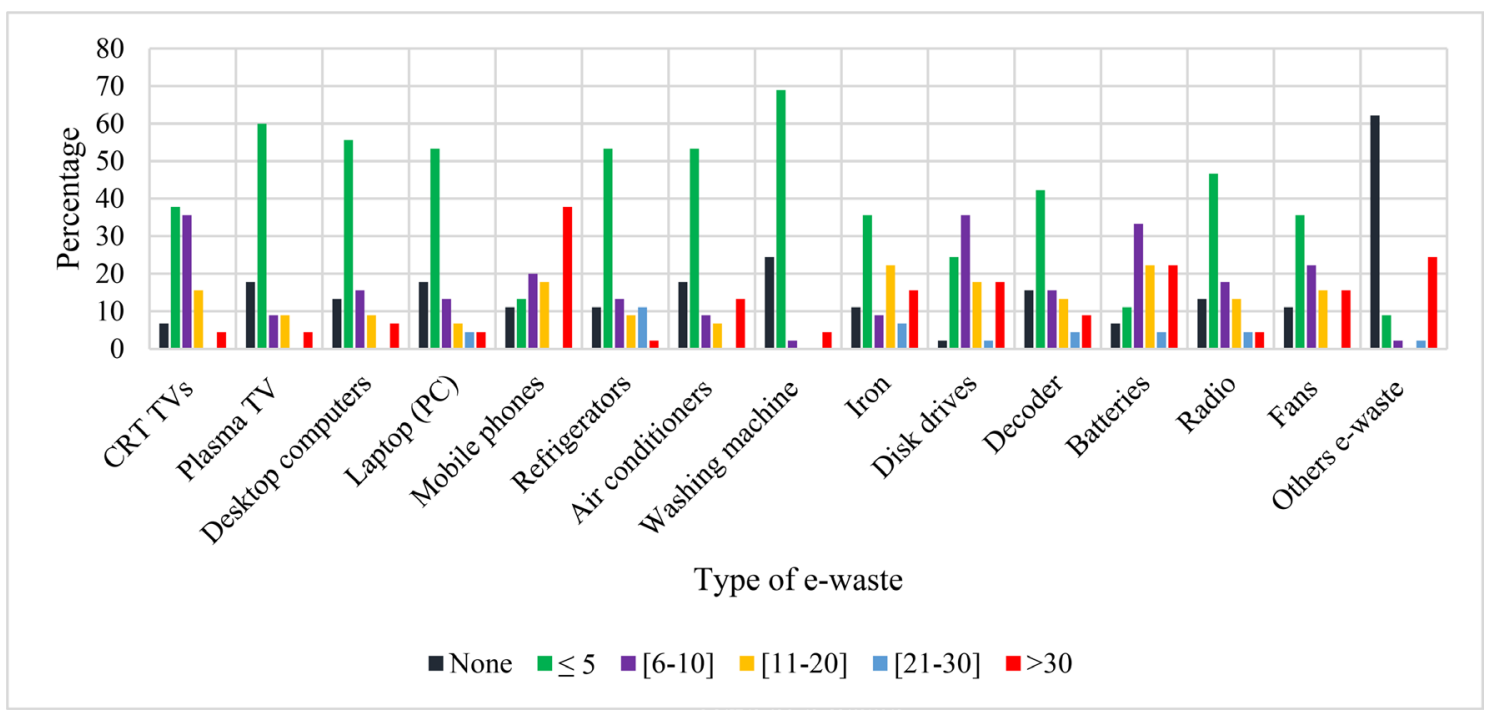

Figure 2. Number of electronic items dismantled by recyclers each month. 


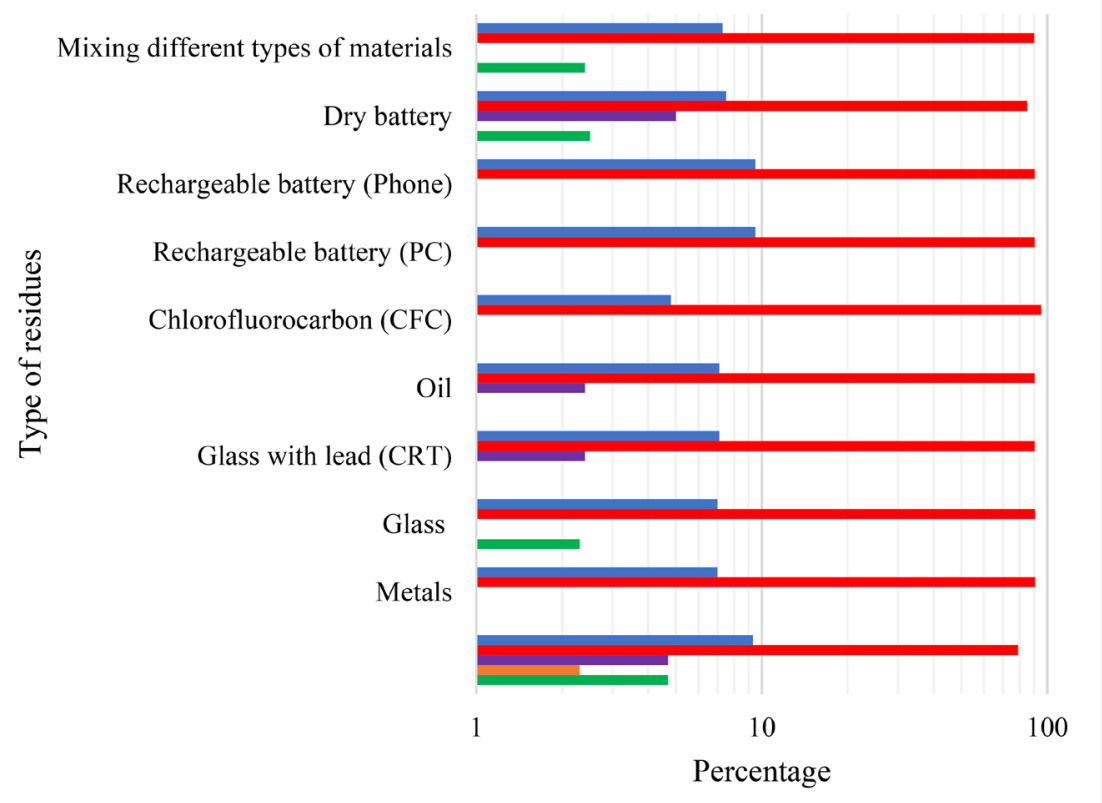

$\square$ Others $\square$ Leave in the wild $\square$ Giving $\square$ Pay for disposal $\square$ Dispose as municipal waste

Figure 3. Method of disposal of e-waste residues.

week in their recycling activities (Figure 3). In general, electrical wires are being burned, and the activities are being carried out on the shore of the Cotonou lagoon (less than one meter from the water).

\subsection{Practices of E-Waste Recyclers}

Most recyclers (64.4\%) indicated that they work more than 8 hours a day, while $8.9 \%$ work 4 to 8 hours a day, and $26.7 \%$ work no more than 4 hours a day. In terms of the number of days they work each week, about half $(46.7 \%)$ of the recyclers work more than 5 days a week while $31.1 \%$ of them work 3 to 5 days a week and $22.2 \%$ work less than 3 days a week.

Just under half (44.2\%) of the recyclers reported wearing at least one PPE. Among recyclers wearing PPE, 37.8\% reported wearing gloves, 33.3\% reported wearing boots and $8.9 \%$ reported wearing glasses. We did not question further on the frequency of use. For those who did not indicate wearing PPE, $28.9 \%$ said that this was due to the lack of financial resources, $26.7 \%$ said that PPE would slow down their work, and $22.2 \%$ said that the use of PPE increases heat and discomfort. Finally, $17.8 \%$ of recyclers do not find it necessary to wear PPE.

In terms of hand washing, about half (51.2\%) of recyclers say they wash their hands before any meal, while $18.6 \%$ of them said they never do while $30.2 \%$ mentioned that they occasionally do so. Respondents also mentioned variable approaches in terms of hand washing. Some (12.8\%) use simple tap water to wash their hands while $28.2 \%$ use this water source with soap. Some (17.9\%) wash their hands with simple well water while $28.2 \%$ use this with soap. It should be noted that $12.8 \%$ admitted to washing their hands with water and 
sand as they believe that this technique allows them to eliminate oils from their hands. It is under these conditions that some recyclers eat at their recycling sites (Figure 4).

More than $90 \%$ of the residues of all materials are left in the wild (Figure 4 and Figure 5). Less than $10 \%$ of the residues are burned in the open air occasionally. In addition, less than $5 \%$ of these residues are offered to individuals who use them to fill swampy areas as landfill to build their homes.

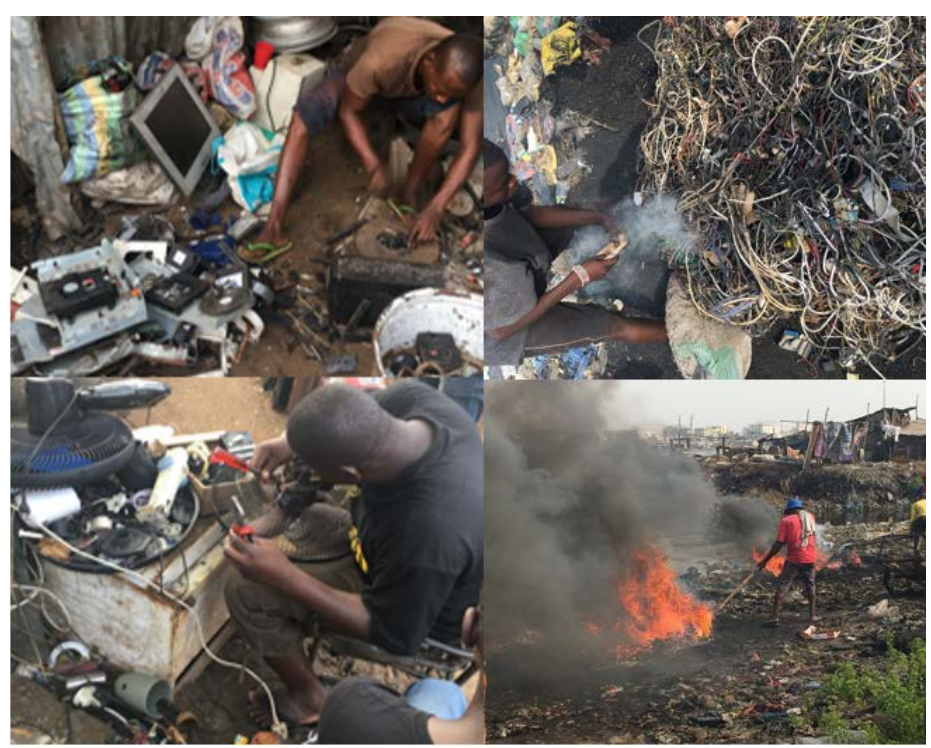

Figure 4. Dismantle and incineration of e-waste in Cotonou workshops which exemplifies the work conditions, notably that activities are generally performed on the bare group and without personal protections.

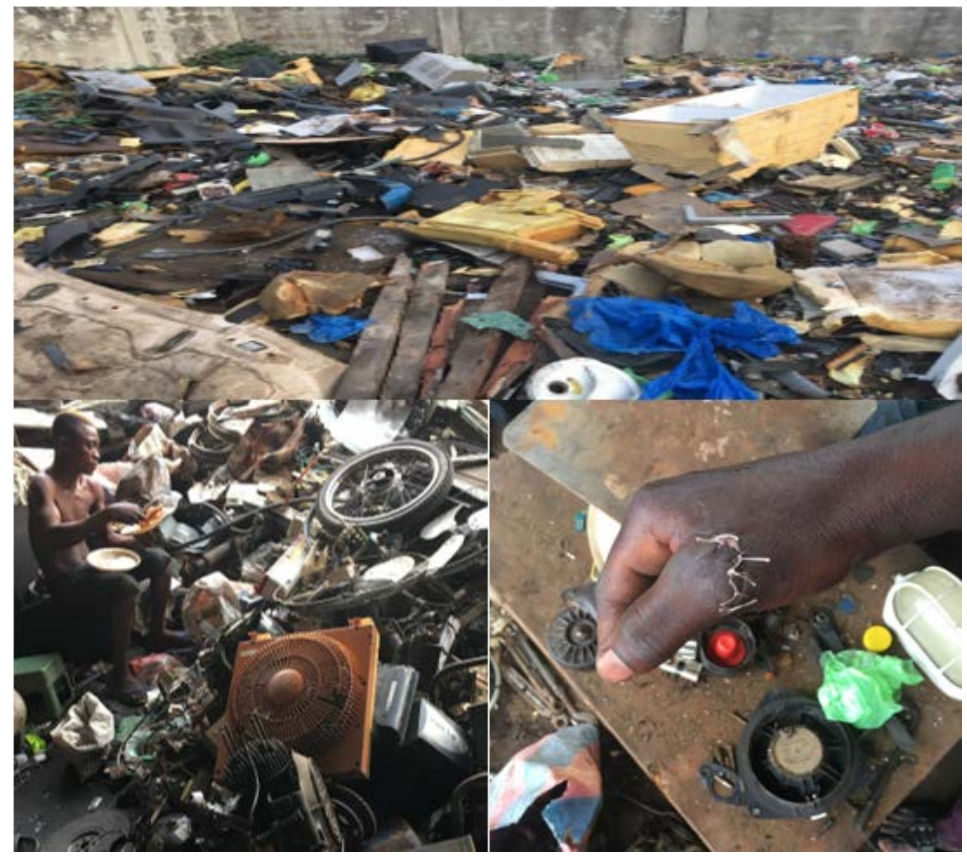

Figure 5. Wild dumping of e-waste residues in Cotonou, recycling worker eating at the workshop and recycling worker with a work accident injury. 


\subsection{Knowledge of Environmental Risks}

Among e-waste recyclers, $73.8 \%$ believed that e-waste recycling can pollute the environment and specifically identified water (46.7\%), soil (71.1\%), air (71.1\%) and food (48.9\%). The remaining one-quarter of respondents did not acknowledge that recycling e-waste can pollute the environment. Instead, they have identified battery acid, engine oils (refrigerators), dust and refrigerant gases, to be the sources of environmental pollution. In terms of dangerous trace elements, the recyclers have identified lead $(\mathrm{Pb})$ as the most well-known elements $(62.3 \%$ are aware of this chemical) followed by arsenic (As) (11.8\%) cadmium (Cd) (5.4\%), chromium $(\mathrm{Cr})(3.9 \%)$ and mercury $(\mathrm{Hg})(2.6 \%)$.

\subsection{Knowledge of Health Risks}

More than $72 \%$ of recyclers believed that recycling e-waste is a risk to their health and well-being. Although only $37.2 \%$ of them think that their activities can be harmful to the health of the general population. In terms of diseases that originated from e-waste sites, they have identified respiratory diseases (67.4\%), heart diseases (62.8\%), eye diseases (65.1\%), kidney diseases (41.9\%) and cancers (30.2\%). In terms of specific substances contained in e-waste the recyclers mentioned acids from all batteries, smoke from incineration, refrigeration gases, motor oils and dust could pose potential health risks to the workers.

Several recyclers reported having experienced the following symptoms (in descending orders) which they attribute to their activities: injury (88.9\%), colds (55.8\%), headache (55.8\%), itching of the skin (45.2\%), cough (44.2\%), wheezing in the breath and airway obstruction (32.6\%), eye irritation (32.6\%), dizziness (32.6\%), nausea $(28.6 \%)$, stomachache $(23.3 \%)$, anorexia (23.3\%), presence of blood in stool (16.3\%) and urine (14\%) and diarrhea (9.3\%). It should be noted that these symptoms were not medically diagnosed but rather self-declarations by the study participants (i.e., recyclers).

To treat these symptoms, recyclers mainly use self-medication $(73.8 \%)$ followed by traditional medicine and homemade family recipes (7.1\%), while $19 \%$ of recyclers do not take any actions and let the symptoms pass on their own.

To scope out possible links between sociodemographic characteristics and self-reported health symptoms, statistical tests were performed (Table 1). As shown in Table 1, the number of electronic items dismantled per month (a proxy for work intensity and thus exposure) is significantly associated with several self-reported symptoms including the presence of blood in the urine and stool, injuries, dizziness, skin itching. The number of hours worked per day is associated with blood in the urine, dizziness, itching of the skin and obstruction of the airways.

Statistical links between the socio-demographic profile of recyclers and their knowledge of the health risks associated with e-waste recycling are demonstrated in Table 2. According to Table 2, there is a statistically significant association between a worker's monthly income and their health status, marital status, 
Table 1. Association between health risks and work intensity and socio-demographic characteristics.

\begin{tabular}{|c|c|c|c|c|c|c|c|c|c|c|c|}
\hline & $\begin{array}{l}\text { Blood in } \\
\text { urine }\end{array}$ & $\begin{array}{l}\text { Blood in } \\
\text { stool }\end{array}$ & Cough & Colds & Injury & Dizziness & $\begin{array}{l}\text { Skin } \\
\text { itching }\end{array}$ & Diarrhea & $\begin{array}{c}\text { Whistling/ } \\
\text { obstruction } \\
\text { of the } \\
\text { airways }\end{array}$ & Headaches & Belly aches \\
\hline \multirow{2}{*}{ Educationallevel } & (None) & (None) & (None) & (None) & (Prim.) & (Prim.) & (Prim.) & (None) & (None) & (None) & (Prim.) \\
\hline & 66.66 & 71.42 & $68.42^{\star}$ & 58.33 & 60 & 50 & 47.36 & 50 & 64.28 & 45.83 & 50 \\
\hline \multirow{2}{*}{ Monthlyincome } & $(50-100 \mathrm{k})$ & $(50-100 \mathrm{k})$ & $(<50 \mathrm{k})$ & $(<50 \mathrm{k})$ & $(<50 \mathrm{k})$ & $(100-200 \mathrm{k})$ & $(<50 \mathrm{k})$ & $(<50 \mathrm{k})$ & $(50-100 \mathrm{k})$ & $(50-100 \mathrm{k})$ & $(50-100 \mathrm{k})$ \\
\hline & 50 & 42.85 & 42.1 & 33.33 & 60 & $42.85^{*}$ & 31.57 & 50 & 35.71 & 33.33 & 50 \\
\hline \multirow{2}{*}{ Marital status } & (Clp.) & (Sing.) & (Sing.) & (Sing.) & (Marié) & (Clp.) & (Sing.) & (Sing.) & (Sing.) & (Sing.) & (Sing.) \\
\hline & $66.66^{\star *}$ & 57.14 & 68.42 & $62.5^{\star}$ & 40 & $50^{* *}$ & $73.68^{* *}$ & 75 & $64.28^{* *}$ & $66.66^{\star *}$ & 70 \\
\hline \multirow{2}{*}{ Smoker } & (No) & (No) & (No) & (No) & (No) & (No) & (No) & (No) & (No) & (No) & (No) \\
\hline & 66.66 & 71.42 & $18.47^{\star}$ & 66.66 & 60 & 50 & 57.89 & 50 & 57.14 & 62.5 & 60 \\
\hline \multirow{2}{*}{ Dismantling } & (Yes) & (Yes) & (Yes) & (Yes) & (Yes) & (Yes) & (Yes) & (Yes) & (Yes) & (Yes) & (Yes) \\
\hline & 100 & $85.71^{*}$ & 94.73 & 95.83 & 100 & 100 & 100 & 100 & 100 & 95.83 & 100 \\
\hline \multirow{2}{*}{$\begin{array}{c}\text { Number of phones } \\
\text { dismantled }\end{array}$} & $(>30)$ & $(>30)$ & $(>30)$ & $(>30)$ & $(>30)$ & $(>30)$ & $(>30)$ & $(>30)$ & $(>30)$ & $(>30)$ & $(>30)$ \\
\hline & $83.33^{\star *}$ & 57.14 & 35.29 & 42.85 & 0 & $61.53^{\star *}$ & 43.75 & 50 & 45.45 & 36.36 & $50^{*}$ \\
\hline \multirow{2}{*}{$\begin{array}{c}\text { Number of } \\
\text { refrigeratorsdismantled }\end{array}$} & $(6-10)$ & $(6-10)$ & $(6-10)$ & $(6-10)$ & $(6-10)$ & $(6-10)$ & $(6-10)$ & $(6-10)$ & $(6-10)$ & $(6-10)$ & $(6-10)$ \\
\hline & 40 & $60^{* *}$ & 16.66 & 18.18 & 50 & 23.07 & 17.64 & 0 & 30 & 20 & 22.22 \\
\hline \multirow{2}{*}{$\begin{array}{c}\text { Number of air } \\
\text { conditioners dismantled }\end{array}$} & $(21-30)$ & $(21-30)$ & $(21-30)$ & $(21-30)$ & $(21-30)$ & $(21-30)$ & $(21-30)$ & $(>30)$ & $(21-30)$ & $(21-30)$ & $(21-30)$ \\
\hline & 40 & $40^{*}$ & 13.33 & 21.05 & $25^{* *}$ & $33.33^{*}$ & $28.57^{*}$ & $50^{*}$ & 33.33 & 20 & 28.57 \\
\hline \multirow{2}{*}{$\begin{array}{c}\text { Number of } \\
\text { irondismantled }\end{array}$} & $(>30)$ & $(>30)$ & $(11-20)$ & $(>30)$ & $(>30)$ & $(>30)$ & $(>30)$ & $(>30)$ & $(>30)$ & $(>30)$ & $(>30)$ \\
\hline & 50 & $50^{*}$ & 26.66 & 33.33 & 25 & $46.15^{\star *}$ & 29.41 & 25 & 33.33 & 22.22 & 40 \\
\hline \multirow{2}{*}{$\begin{array}{l}\text { Number of disassembled } \\
\text { disk drives }\end{array}$} & $(>30)$ & $(>30)$ & $(\leq 5)$ & $(\leq 5)$ & $(>30)$ & $(>30)$ & $(\leq 5)$ & $(>30)$ & $(\leq 5)$ & $(\leq 5)$ & $(>30)$ \\
\hline & 33.33 & $28.57^{*}$ & 26.31 & 25 & 20 & $28.57^{*}$ & 21.05 & $25^{*}$ & 28.57 & 25 & 30 \\
\hline \multirow{2}{*}{$\begin{array}{c}\text { Number of } \\
\text { decodersdismantled }\end{array}$} & $(>30)$ & $(>30)$ & $(\leq 5)$ & $(>30)$ & $(>30)$ & $(>30)$ & $(>30)$ & $(\leq 5)$ & $(>30)$ & $(\leq 5)$ & $(>30)$ \\
\hline & 40 & $50^{*}$ & 20 & 15.78 & $20^{* *}$ & 23.07 & 20 & 33.33 & 27.27 & 20 & 25 \\
\hline \multirow{2}{*}{$\begin{array}{c}\text { Number of working } \\
\text { hours/day }\end{array}$} & $(\leq 4 \mathrm{~h})$ & $(\leq 4 \mathrm{~h})$ & $(>8 \mathrm{~h})$ & $(<8 \mathrm{~h})$ & $(>8 \mathrm{~h})$ & $(\leq 4 \mathrm{~h})$ & $(>8 \mathrm{~h})$ & $(>8 \mathrm{~h})$ & $(\leq 4 \mathrm{~h})$ & $(>8 \mathrm{~h})$ & $(\leq 4 \mathrm{~h})$ \\
\hline & $66.66^{*}$ & 42.85 & 68.42 & 54.16 & 80 & $50^{* *}$ & $47.36^{*}$ & 75 & $42.85^{*}$ & 58.33 & 50 \\
\hline
\end{tabular}

${ }^{*} \mathrm{p} \leq 0.05 ;{ }^{* *} \mathrm{p} \leq$ 0.01; (Dominant modality) Percentage; Prim. = Primary; Clp. = Common-law partnership; Sing. = Single.

Table 2. Association between the socio-demographic profile of recyclers and knowledge of health risks.

\begin{tabular}{|c|c|c|c|c|c|c|c|c|}
\hline & $\begin{array}{l}\text { Respiratory } \\
\text { diseases }\end{array}$ & Heart diseases & Eye diseases & Kidney diseases & Cancer & $\begin{array}{l}\text { E-waste contain } \\
\text { substances that } \\
\text { are hazardous } \\
\text { to the health of } \\
\text { recyclers }\end{array}$ & $\begin{array}{l}\text { E-waste contain } \\
\text { substances } \\
\text { dangerous to the } \\
\text { health of general } \\
\text { population }\end{array}$ & $\begin{array}{l}\text { Perception of } \\
\text { healthstatus }\end{array}$ \\
\hline Monthlyincome & $\begin{array}{c}(-50 \mathrm{k}) \\
37.93\end{array}$ & $\begin{array}{c}(50-100 \mathrm{k}) \\
37.03\end{array}$ & $\begin{array}{c}(-50 \mathrm{k}) \\
39.28\end{array}$ & $\begin{array}{c}(50-100 \mathrm{k}) \\
44.44\end{array}$ & $\begin{array}{c}(50-100 \\
\mathrm{k}) \\
46.15\end{array}$ & $\begin{array}{c}(50-100 \mathrm{k}) \\
38.7\end{array}$ & $\begin{array}{c}(-50 \mathrm{k}) \\
37.5\end{array}$ & $\begin{array}{c}(50-100 \mathrm{k}) \\
(\text { excel }) \\
56.52^{\star}\end{array}$ \\
\hline Marital status & $\begin{array}{l}\text { (Sing.) } \\
72.41^{\star}\end{array}$ & $\begin{array}{l}\text { (Sing.) } \\
66.66\end{array}$ & $\begin{array}{l}\text { (Sing.) } \\
71.42\end{array}$ & $\begin{array}{l}\text { (Sing.) } \\
66.66\end{array}$ & $\begin{array}{l}\text { (Sing.) } \\
61.53\end{array}$ & $\begin{array}{l}\text { (Sing.) } \\
61.29\end{array}$ & $\begin{array}{l}\text { (Sing.) } \\
62.5\end{array}$ & $\begin{array}{c}\text { (Sing.) } \\
(\text { excel) } \\
52.17\end{array}$ \\
\hline $\begin{array}{l}\text { Seniority in } \\
\text { work }\end{array}$ & $\begin{array}{c}(1-3 \text { years }) \\
27.58\end{array}$ & $\begin{array}{c}\text { (+10 years) } \\
22.22\end{array}$ & $\begin{array}{c}(1-3 \text { years }) \\
31.03\end{array}$ & $\begin{array}{c}(5-10 \text { years }) \\
27.77\end{array}$ & $\begin{array}{c}(-1 \text { an }) \\
30.76\end{array}$ & $\begin{array}{c}(1-3 \text { years }) \\
25.8\end{array}$ & $\begin{array}{c}(1-3 \text { years }) \\
37.5^{\star}\end{array}$ & $\begin{array}{c}\text { (1-3 years) } \\
\text { (excel) } \\
30.43\end{array}$ \\
\hline Smoker & $\begin{array}{l}\text { (Yes) } \\
62.5\end{array}$ & $\begin{array}{l}\text { (Yes) } \\
62.5^{* *}\end{array}$ & $\begin{array}{l}\text { (Yes) } \\
50\end{array}$ & $\begin{array}{l}\text { (Yes) } \\
62.5\end{array}$ & $\begin{array}{l}\text { (Yes) } \\
37.5\end{array}$ & $\begin{array}{l}\text { (Yes) } \\
75\end{array}$ & $\begin{array}{l}\text { (Non) } \\
56.25\end{array}$ & $\begin{array}{c}\text { (Yes) } \\
\text { (excel) } \\
50\end{array}$ \\
\hline
\end{tabular}

${ }^{*} \mathrm{p} \leq 0.05 ;{ }^{* *} \mathrm{p} \leq 0.01 ;$ (Dominant modality) Percentage; $\mathrm{k}=1000 ;$ Excel. $=$ Excellent; Sing. $=$ Single. 
respiratory disease, job seniority, and knowledge of health risk for the general population, and between smoking and knowledge of heart disease risk.

Finally, according to recyclers, $60.5 \%$ of them have been unable to work due to tiredness or weakness due to work pressure. The duration of this fatigue among respondents varies in the following order: one day $(39.3 \%)>$ of the respondents, 2 days $(28.6 \%)>, 3$ days (17.9\%), and more than 3 days (14.3\%).

\section{Discussion}

The knowledge and practices of e-waste recyclers were analyzed via this crosssectional study. From this study, e-waste recycling activities do not involve women. This has been observed in other studies of e-waste workers. For instance, Yu, Akormedi [7] also documented that e-waste recycling is a male-only activity with women working in supporting industries (e.g., food preparation) in Ghana, Ohajinwa, van Bodegom [19] also found that males were 99\% represented. The result of our study indicated that the demographic variation of recyclers largely involves young and poorly educated workers.

It should be recalled that more than $70 \%$ of recyclers earn less than 100,000 fcfa per month, or about 170 USD. These results are similar to those of Yu, Akormedi [7] from Ghana. Paradoxically, Agyei-Mensah and Oteng-Ababio [14] in a study conducted in Ghana found that e-waste workers could earn on average between US $\$ 377$ and US $\$ 445$, twice as much as this study reports here from Benin. The study by Zhang, Schnoor [6] conducted in India found that workers who strip electrical wires can earn about US $\$ 80$ in 5 days.

Most of recyclers have at most 5 years of experience in e-waste recycling which suggests that the sector is relatively new. According to the result of our interview, $70 \%$ of recyclers have no other professional activity. These results are different from surveys of e-waste workers from across China, [6] [24], India [25] [26], in Nigeria [27] and in Ghana [28] where the e-waste recycling chain was born earlier. As shown in several other studies, the main recycling activities are, respectively, dismantling [7] [29] [30], sorting [7] [31] and burning [28] [32] of e-waste, which align with what we report here.

Recyclers process significant quantities of e-waste per month. Most of recyclers (64.4\%) worked more than 8 hours per day, about half $(46.7 \%)$ of them worked more than 5 days per week. In their daily work, they give themselves very little rest as stated by other studies (Yu, Akormedi [7], Tukker, Buist [33], Zinjarde, Apte [34], Singh, Thind [35]. Moreover, the current study shows a link between the workload (number of e-waste dismantled) and the symptoms experienced.

Another issue that may pose health risks to recyclers is no use of PPE. Studies conducted on recyclers in Nigeria and Nepal indicated that over $50 \%$ of workers do not use PPE [13] [15]. This is in line with our findings that only (44.2\%) of the recyclers used PPE and that is mostly due to discomfort, cost, unnecessary and slower work; same reasons as those reported by another research conducted 
in Nigeria [19].

It should be noted that recyclers commonly eat at recycling sites. In the current study about half the population will wash their hands prior to eating, which is lower than the study by Ohajinwa, Van Bodegom [13] who reported that most recyclers in Nigeria (68.5\%) wash their hands before meals at the sites.

Recyclers are aware that their activities can pollute the soil and air but ignore the risk to water and food; this could be explained by the fact that they operate directly on bare soil and in the open air. This result is relatively different from that of Agyei-Mensah and Oteng-Ababio [14], who found that barely half of recyclers are aware that their activities can pollute the air. Recyclers are somewhat aware that their work pollutes the environment, but they chose to continue due to lack of jobs. Recyclers in general do not have any knowledge of the pollutants that their activities can generate. Ohajinwa, Van Bodegom [13] also found that $88 \%$ of recyclers in Nigeria are unaware of the hazardous chemical pollutants contained in e-waste.

Regarding health, most recyclers (i.e., 72\%) were aware that their activities pose health risks to them. This result contradicts that of Ohajinwa, Van Bodegom [13] who found out that only $30 \%$ of recyclers in Nigeria perceive the risk to their own health. In the current study, the recyclers have reported several symptoms that could be associated with contamination of their bodies as in several other studies [7] [14] [15] [36] [37]. However, the current study collected these symptoms based on participants' reports. The next step would be to carry out medical studies and epidemiological research to establish associations between work activities and chemical exposures with health measures. While the majority of recyclers recognize a possible link between respiratory, cardiac and eye diseases, they are unaware of the carcinogenic potential of the chemicals contained in e-waste. Agyei-Mensah and Oteng-Ababio [14] also found that only $3 \%$ of recyclers in Ghana knew that the chemicals they routinely handled may be carcinogenic. Of all the potential hazards associated with e-waste, the best perceived by recyclers is the injury (88.9\%). Black, Karki [15] also found the same result in Nepal where they found an injury prevalence of over $80 \%$. A significant injury prevalence was also found in Ghana (50\%) [14]. While workplace injuries for e-waste recyclers in Nigeria are reported to be as high as $68 \%$, the majority of recyclers (i.e., 90\%) are not worried about these injuries [19] Ohajinwa, Van Bodegom [13]. This is most likely due to the search for the financial benefit that matters more than anything else to them. The results of our study indicated that while recyclers are generally aware that their activities pose serious risks to their own health, they are not aware that their activities may extend the health hazards to people living in proximity to the recycling sites. This is in accordance with the findings of Yu, Akormedi [7] study that reported the majority of recyclers have limited knowledge of the risks posed to the general population. Several studies have proven the existence of these risks and crop consumption was reported as the main exposure pathway [38] [39] [40]. At the 
onset of symptoms, recyclers first resort to self-medication, traditional medicine or homemade family recipes. Some even let the symptoms disappear on their own. Yu, Akormedi [7] reported the same result in their study in Ghana.

Our study had several limitations; firstly, the lack of data regarding the number of e-waste recyclers did not allow us to determine the sample size using a statistical protocol. This could have an impact on the representativeness of the e-waste recyclers. Nevertheless, this bias was controlled by including all e-waste recyclers available during the study period and at several (larger) recycling sites. Secondly, the symptoms reported in this study were based on participants' self-reporting (questionnaire) and not on a medical consultation basis. Note that this study gives an overview of the situation of knowledge and practices of e-waste recyclers in Cotonou, thus, the results should be interpreted with caution.

\section{Conclusions}

This study analyzed the knowledge of health and environmental risks as well as the practices of e-waste recyclers in Cotonou in which we considered the socio-demographic characteristics, professional profile, knowledge and practices of e-waste recyclers.

Recyclers have limited knowledge of the risks that their daily activities may pose to the environment and human health. Their practices often reflect ignorance of the seriousness of their actions and sometimes a lack of financial resources to adopt safe and environmentally friendly behaviors. It is therefore imperative to develop and implement environmental health education policies adapted to the e-waste recycling sector. Regarding education and prevention, it will be necessary to raise awareness among those involved in e-waste recycling, including recyclers, about the risks (environment and health) and the importance of acting. This will help better inform recyclers and their employers about the dangers associated with their activities. There is limited support from public authorities for e-waste workers, thus, there should be national and international standards to enforce local occupational health and the health and well-being of recyclers.

Beyond self-reporting of health consequences, future research should consider medical consultations to establish the certainty of disease occurrence due to informal e-waste recycling. Due to its novelty in Benin, the present study could nevertheless be used as a reference not only to carry out purely medical studies but also to give the interest for the public authority to count the workers in the e-waste recycling sector while regularizing the sector. Concerning regulation, it will be necessary to adopt regulatory texts that prohibit not only traditional and informal recycling without the recommended technologies but also any nuisance that may result from recycling activities. In addition, the social and environmental responsibility of companies that recycle e-waste will have to be encouraged.

\section{Acknowledgements}

The authors acknowledge the financial support from Canada's International 
Development Research Centre and the U.S. National Institutes of Health's Global Environmental and Occupational Health program (funding number U01TW010103) to achieve this work. We also thank Dr. Nasrin Golzadeh for proofreading this work.

\section{Data Accessibility}

Data set of this study is available from the corresponding authors.

\section{Conflicts of Interest}

The authors declare no conflicts of interest regarding the publication of this paper.

\section{References}

[1] Merot, A.-S., Grazzini, F. and Boissin, J.-P. (2014) Gouvernance et développement durable: Le cas de la responsabilité élargie du producteur dans une filière de gestion des déchets.

[2] Bahers, J.-B., Capurso, I. and Gossart, C. (2015) Réseaux et environnement: Regards croisés sur les filières de gestion des Déchets d'Équipement Électriques et Électroniques à Toulouse et à Milan. Flux, 1, 32-46. https://doi.org/10.3917/flux.099.0032

[3] Balde, C.P., et al. (2017) The Global E-Waste Monitor 2017: Quantities, Flows and Resources. United Nations University, International Telecommunication Union, and International Solid Waste Association, 2017.

[4] Boudier, F. and Bensebaa, F. (2011) Hazardous Waste Management and Corporate Social Responsibility: Illegal Trade of Electrical and Electronic Waste. Business and Society Review, 116, 29-53. https://doi.org/10.1111/j.1467-8594.2011.00376.x

[5] Bensebaa, F. and Boudier, F. Développement durable et territories, Varia.

[6] Zhang, K., Schnoor, J.L. and Zeng, E.Y. (2012) E-Waste Recycling: Where Does It Go from Here? Environmental Science \& Technology, 46, 10861-10867. https://doi.org/10.1021/es303166s

[7] Yu, E.A., Akormedi, M., Asampong, E., Meyer, C.G. and Fobil, J.N. (2017) Informal Processing of Electronic Waste at Agbogbloshie, Ghana: Workers' Knowledge about Associated Health Hazards and Alternative Livelihoods. Global Health Promotion, 24, 90-98. https://doi.org/10.1177/1757975916631523

[8] Yang, H., Ma, M., Thompson, J.R.R. and Flower, J. (2018) Waste Management, Informal Recycling, Environmental Pollution and Public Health. Journal of Epidemiology and Community Health, 72, 237-243. https://doi.org/10.1136/jech-2016-208597

[9] Schmidt, C.W. (2006) Unfair Trade: E-Waste in Africa. Environmental Health Perspectives, 114, 232-235. https://doi.org/10.1289/ehp.114-a232

[10] Zhang, W.H., Wu, Y.X. and Simonnot, M.O. (2012) Soil Contamination due to E-Waste Disposal and Recycling Activities: A Review with Special Focus on China. Pedosphere, 22, 434-455. https://doi.org/10.1016/S1002-0160(12)60030-7

[11] Zounkova, R., Jalova, V., Janisova, M., Ocelka, T., et al. (2014) In situ Effects of Urban River Pollution on the Mudsnail Potamopyrgus antipodarum as Part of an Integrated Assessment. Aquatic Toxicology, 150, 83-92. https://doi.org/10.1016/j.aquatox.2014.02.021 
[12] Yang, Y.C., Xue, M.Q., Xu, Z.M. and Huang, C. (2013) Health Risk Assessment of Heavy Metals (Cr, Ni, Cu, $\mathrm{Zn}, \mathrm{Cd}, \mathrm{Pb}$ ) in Circumjacent Soil of a Factory for Recycling Waste Electrical and Electronic Equipment. Journal of Material Cycles and Waste Management, 15, 556-563. https://doi.org/10.1007/s10163-013-0120-2

[13] Ohajinwa, C.M., Bodegom, P.M.V., Vijver, M.G. and Peijnenburg, W.J.G.M. (2017) Health Risks Awareness of Electronic Waste Workers in the Informal Sector in Nigeria. International Journal of Environmental Research and Public Health, 14, 911. https://doi.org/10.3390/ijerph14080911

[14] Agyei-Mensah, S. and Oteng-Ababio, M. (2012) Perceptions of Health and Environmental Impacts of E-Waste Management in Ghana. International Journal of Environmental Health Research, 22, 500-517.

https://doi.org/10.1080/09603123.2012.667795

[15] Black, M., Karkib, J. Lee, A.C.K., Makaib, P., Baralb, Y.R., et al. (2019) The Health Risks of Informal Waste Workers in the Kathmandu Valley: A Cross-Sectional Survey. Public Health, 166, 10-18. https://doi.org/10.1016/j.puhe.2018.09.026

[16] Srigboh, R.K., Basu, N., Stephens, J. Asampong, E., et al. (2016) Multiple Elemental Exposures amongst Workers at the Agbogbloshie Electronic Waste (E-Waste) Site in Ghana. Chemosphere, 164, 68-74.

https://doi.org/10.1016/j.chemosphere.2016.08.089

[17] Fischer, D., Seidu, F., Yang, J., Felten M.K. et al. (2020) Health Consequences for E-Waste Workers and Bystanders-A Comparative Cross-Sectional Study. International Journal of Environmental Research and Public Health, 17, 1534. https://doi.org/10.3390/ijerph17051534

[18] Cazabon, D., Fobil, J.N., Essegbey, G. and Basu, N. (2017) Structured Identification of Response Options to Address Environmental Health Risks at the Agbogbloshie Electronic Waste Site. Integrated Environmental Assessment and Management, 13, 980-991. https://doi.org/10.1002/ieam.1964

[19] Ohajinwa, C.M., van Bodegom, P.M., Vijver, M.G., Olumide, A.O., et al., (2018) Prevalence and Injury Patterns among Electronic Waste Workers in the Informal Sector in Nigeria. Injury Prevention, 24, 185-192. https://doi.org/10.1136/injuryprev-2016-042265

[20] Alabi, A.O. and Bakare, A.A. (2017) Genetic Damage Induced by Electronic Waste Leachates and Contaminated Underground Water in Two Prokaryotic Systems. Toxicology Mechanisms and Methods, 27, 657-665. https://doi.org/10.1080/15376516.2017.1349228

[21] Heacock, M., Trottier, B., Adhikary, S., Asante, K.A., Basu, N. et al. (2018) Prevention-Intervention Strategies to Reduce Exposure to E-Waste. Reviews on Environmental Health, 33, 219-228. https://doi.org/10.1515/reveh-2018-0014

[22] Basu, N., Ayelo, P.A., Djogbénou, L.S., Kedoté, M., et al., (2016) Occupational and Environmental Health Risks Associated with Informal Sector Activities-Selected Case Studies from West Africa. NEW SOLUTIONS: A Journal of Environmental and Occupational Health Policy, 26, 253-270. https://doi.org/10.1177/1048291116651726

[23] Earth, P.G. (2009) The E-Waste Inventory Project in Malaysia. Department of Environment, Malaysia \& EX-Corporation, Japan.

[24] Li, J., Yang, J. and Liu, L. (2015) Development Potential of E-Waste Recycling Industry in China. Waste Management \& Research, 33, 533-542. https://doi.org/10.1177/0734242X15584839

[25] Ha, N.N., Agusa, T., Ramua, K., et al. (2009) Contamination by Trace Elements at 
E-Waste Recycling Sites in Bangalore, India. Chemosphere, 76, 9-15. https://doi.org/10.1016/j.chemosphere.2009.02.056

[26] Awasthi, A.K., Zeng, X. and Li, J.H. (2016) Relationship between E-Waste Recycling and Human Health Risk in India: a Critical Review. Environmental Science and Pollution Research, 23, 11509-11532. https://doi.org/10.1007/s11356-016-6085-7

[27] Alabi, O.A., Bakare, A.A. Xua, X.J., Li, B. Zhang, Y.L., Huo, X., et al., (2012) Comparative Evaluation of Environmental Contamination and DNA Damage Induced by Electronic-Waste in Nigeria and China. Science of the Total Environment, 423, 62-72. https://doi.org/10.1016/j.scitotenv.2012.01.056

[28] Nkrumah, P.N., et al. (2013) Primitive E-Waste Recycling Practices in Ghana: The Releases and Effects of Persistent Organic Pollutants on the Aquatic Environment. Proceedings of the 35th IAHR World Congress, VOLS I and II, Beijing, 2013, 3433-3440.

[29] Zhang, J.L., Ding, J.F., Lu, G.N., Dang, Z. and Yi, X.Y. (2015) Heavy Metal Contamination in Farmland Soils at an E-Waste Disassembling Site in Qingyuan, Guangdong, South China. Environmental Science, 36, 2633-2640.

[30] Zeng, X.L., Li, J.H., Xie, H.H. and Liu, L.L. (2013) A Novel Dismantling Process of Waste Printed Circuit Boards Using Water-Soluble Ionic Liquid. Chemosphere, 93, 1288-1294. https://doi.org/10.1016/j.chemosphere.2013.06.063

[31] Zhang, L.G. and Xu, Z.M. (2016) A Review of Current Progress of Recycling Technologies for Metals from Waste Electrical and Electronic Equipment. Journal of Cleaner Production, 127, 19-36. https://doi.org/10.1016/j.jclepro.2016.04.004

[32] Sthiannopkao, S. and Wong, M.H. (2013) Handling E-Waste in Developed and Developing Countries: Initiatives, Practices, and Consequences. Science of the Total Environment, 463, 1147-1153. https://doi.org/10.1016/j.scitotenv.2012.06.088

[33] Tukker, A., Buist, H., Oersc, L. and van der Voetc, E. (2006) Risks to Health and Environment of the Use of Lead in Products in the EU. Resources, Conservation and Recycling, 49, 89-109. https://doi.org/10.1016/j.resconrec.2006.03.005

[34] Zinjarde, S., Apte, M., Mohite, P. and Ravi Kumar, A. (2014) Yarrowia lipolytica and Pollutants: Interactions and Applications. Biotechnology Advances, 32, 920-933. https://doi.org/10.1016/j.biotechadv.2014.04.008

[35] Singh, M., Thind, P.S. and John, S. (2018) Health Risk Assessment of the Workers Exposed to the Heavy Metals in E-Waste Recycling Sites of Chandigarh and Ludhiana, Punjab, India. Chemosphere, 203, 426-433. https://doi.org/10.1016/j.chemosphere.2018.03.138

[36] Wang, D.G., Alaee, M., Byer, J.D. Brimble, S. and Pacepavicius, G. (2013) Human Health Risk Assessment of Occupational and Residential Exposures to Dechlorane Plus in the Manufacturing Facility Area in China and Comparison with E-Waste Recycling Site. Science of the Total Environment, 445-446, 329-336. https://doi.org/10.1016/j.scitotenv.2012.12.059

[37] Han, Z.X., Wang, N., Zhang, H.L. and Yang, X.Y. (2017) Heavy Metal Contamination and Risk Assessment of Human Exposure Near an E-Waste Processing Site. Acta Agriculturae Scandinavica, Section B-Soil \& Plant Science, 67, 119-125. https://doi.org/10.1080/09064710.2016.1229016

[38] Yu, Y., Zhu, X.H., Li, L.Z., Lin, B.G., Xiang, M.D., Zhang, X.H., et al. (2019) Health Implication of Heavy Metals Exposure via Multiple Pathways for Residents Living Near a Former E-Waste Recycling Area in China: A Comparative Study. Ecotoxicology and Environmental Safety, 169, 178-184. https://doi.org/10.1016/j.ecoenv.2018.10.115 
[39] Neeratanaphan, L., Khamma, S., Benchawattananon, R., Ruchuwararak, P., et al. (2017) Heavy Metal Accumulation in Rice (Oryza sativa) Near Electronic Waste Dumps and Related Human Health Risk Assessment. Human and Ecological Risk Assessment, 23, 1086-1098. https://doi.org/10.1080/10807039.2017.1300856

[40] Luo, C.L., Liu, C.P., Wang, Y., Liu, X., Li, F.B., et al. (2011) Heavy Metal Contamination in Soils and Vegetables Near an E-Waste Processing Site, South China. Journal of Hazardous Materials, 186, 481-490.

https://doi.org/10.1016/j.jhazmat.2010.11.024 